\title{
Accessing Care Through the Veterans Choice Program: The Veteran Experience
}

\author{
George G. Sayre, PsyD ${ }^{1,2}$, Emily L. Neely, MPH ${ }^{7}$, Carol E. Simons, BA ${ }^{7}$, Christine A. Sulc, BA ${ }^{7}$, \\ David H. Au, MD ${ }^{1,3}$, and P. Michael Ho, MD, $P h D^{4,5}$
}

IVA Puget Sound Health Care System, Center of Innovation for Veteran-Centered and Value-Driven Care, Seattle, WA, USA; ${ }^{2}$ Department of Health Services, University of Washington School of Public Health, Seattle, WA, USA; ${ }^{3}$ Division of Pulmonary and Critical Care Medicine, Department of Medicine, University of Washington, Seattle, WA, USA; 'VA Eastern Colorado Health Care System, Center of Innovation for Veteran-Centered and Value-Driven Care, Denver, CO, USA; ${ }^{5}$ University of Colorado School of Medicine, Aurora, CO, USA.

\begin{abstract}
BACKGROUND: The Veterans Choice Program (VCP) was implemented to improve healthcare access by expanding healthcare options for Veterans Health Administration (VHA) enrollees.
\end{abstract}

OBJECTIVES: To understand Veterans' experience accessing VCP care.

DESIGN: Qualitative content analysis.

SUBJECTS: Forty-seven veterans from three medical centers in three of the five VA geographical regions.

APPROACH: We used semi-structured telephone interviews designed to elicit descriptions of Veterans' experiences. Data was analyzed using iterative, inductive, and deductive content analysis. Broad themes were identified based on representative interview responses.

KEY RESULTS: We identified six themes: general impressions (concept and frustration); preferred source of care (institution, specialty, and individual provider); facilitators (VA staff facilitation and proactive Veterans); barriers (complexity, lack of responsiveness, lack of local providers, and poor coordination); perceived sources of VCP problems (learning curve, leadership and staff, and politics); and unintended negative impact (responsibility for costs of care and discontinued access to community care). DISCUSSION: Most Veterans who had received care through the VCP felt that it improved their access to care. However, accessing care through the VCP is a complex process that requires proactive Veterans and active support from the VA, third-party administrators, and availability of participating community providers. Veterans' abilities to navigate this process and the level of support provided varied widely. Even patients who did receive care through VCP found the process challenging. Greater support is needed for some Veterans to successfully access VCP care because Veterans who need care the most may be the least able to access it.

KEY WORDS: Veterans; access to care; qualitative research; program evaluation; care transitions.

J Gen Intern Med 33(10):1714-20

DOI: $10.1007 / \mathrm{s} 11606-018-4574-8$

(C) Society of General Internal Medicine (This is a U.S. government work and not under copyright protection in the U.S.; foreign copyright protection may apply) 2018

Received December 7, 2017

Revised June 13, 2018

Accepted July 2, 2018

Published online July 23, 2018

\section{INTRODUCTION}

In January 2014, the Department of Veterans Affairs (VA) was confronted with significant public outcry regarding excessive wait times for Veterans to receive care and potential adverse consequences. In response, Congress passed the Veterans Access, Choice, and Accountability Act of 2014 (VACAA). ${ }^{1-6}$ A key component of the VACAA was the Veterans Choice Program (VCP), which allows Veterans who have wait times of 30 days or longer, or live more than 40 miles from the nearest VA facility, to receive care paid for by the VA from contracted non-VA providers. ${ }^{2,3,7-9}$ All enrolled Veterans were mailed program information in late 2014. ${ }^{10}$

To facilitate implementation of the program, the VA contracted with two third-party administrators (TPAs) to verify Veteran eligibility, contract with non-VA providers, transfer medical records, and authorize care. ${ }^{10-12}$ VCP appointments were made through the TPA and Veterans had limited input in choosing their provider(s) and location(s). Eligible Veterans were able to use the program starting November 5, 2014. ${ }^{10}$ By April 2015, less than 6 months after inception, the VA had scheduled more than 45,000 Choice Program medical appointments. ${ }^{7}$

Implementing a program of this size and complexity in the required timeframe presented significant challenges, and initial participation was lower than expected. ${ }^{9}$ A recent qualitative study of VA staff and providers concluded that the VCP was implemented too rapidly with inadequate preparation, resulting in insufficiently developed community provider networks and communication and scheduling challenges with community provider subcontractors. ${ }^{13}$ When implementing significant changes within large healthcare-delivery systems, it is critical to have early feedback from a variety of program participants to fully understand the impacts. Qualitative research is well-suited to understanding the complex and ongoing interactions related to healthcare system changes and identifying previously unidentified factors for further investigation. ${ }^{14-16}$ Although there have been previous qualitative studies examining the impact of the VCP from the perspective of providers and staff, none have looked at the program from the Veteran's perspective. ${ }^{13,17}$ As part of a larger multi-site, multi-method evaluation of the VCP, we interviewed Veterans who had sought VCP care in order to understand their 
experiences, as well as identify unintended consequences and barriers and facilitators to accessing VCP care. These findings have significant implications given the VA's goal, as stated by then Under Secretary David Shulkin, to "expand our methods of providing care" and adopt a "Veteran-centric approach in everything we do."

\section{METHODS}

This qualitative study was part of a larger multi-site, multimethod evaluation of the VCP using a convenience sample from three VA medical centers (VAMCs) collocated with the evaluation center sites and included both TPAs.

\section{Recruitment and Participants}

Two groups of Veterans were purposively sampled from each of the three evaluation sites to include participants identified by local VA-VCP coordinators as belonging to either of the following groups: (1) Veterans who had received care through VCP (VCP care receivers) and (2) Veterans who had sought care through VCP but did not receive care (unsuccessful VCP care seekers). Eligibility and utilization data was obtained from local sites' Choice Program administrators and then checked against VA databases to verify the Veteran's group status at the time of interview. Veterans from both groups were identified randomly at each site. Veterans agreed to participate in response to mail solicitation or subsequent phone contact.

\section{Procedures}

Semi-structured interview guides were developed by the research team guided by the Consolidated Framework for Implementation Research $(\mathrm{CFIR})^{18}$ (see Appendix 1) to elicit rich responses to a variety of aspects of patient needs and resources including choices, barriers and facilitators to utilization, and satisfaction. The guides (see Appendix X) included open-ended questions and semi-structured probes to ensure uniform data collection of key topics. This also allowed for exploration of unanticipated themes generated by participants. Evaluation team members at each site (nine total) were trained in qualitative interviewing by each site's qualitative lead. Telephone interviews ranged in length from 6 to $67 \mathrm{~min}$ (average 27) and were recorded to assure accuracy. Interview recordings were reviewed and transcribed.

\section{Analysis}

Data collection and analysis were conducted concurrently. Analysis was done by the lead author (G.S., psychologist) using deductive and inductive content analysis. ${ }^{19}$ Transcripts were uploaded to ATLAS.ti (v7.5.18, Scientific Software Development GmbH, Berlin, Germany) for coding and data management. Coding was conducted using audio recordings and transcriptions simultaneously to ensure transcription fidelity and capture participant inflection not contained in transcripts. Deductive content analysis consisted of identifying quotes and phrases that fit within pre-identified and defined a-priori categories. A-priori categories included general impressions and acceptability, care preferences, and barriers and facilitators to accessing VCP care. Inductive content analysis entailed open/unstructured coding, and allowed for the identification of emergent, previously unidentified or unexpected themes, to capture data that did not fit into a-priori categories. Coding continued until thematic saturation (e.g., the point at which subsequent data failed to produce new findings). ${ }^{20}$

\section{RESULTS}

We interviewed 47 Veterans between June and October 2015. Respondents' age ranged from 53 to 91 (mean age 67) (see Table 1). Respondents were predominately male (95\%) with 2 females $(5 \%)$, which is under the national average of $9 \%$ total female Veterans. Saturation was reached after analysis of 43 (41 male and 2 female) interviews of the total sample size.

Local site coordinators dichotomously identified Veterans who had received care and those who had not. However, we found that individual Veterans who were categorized as receiving care had varied experiences in accessing care. Some obtained VCP care for all of the services they sought while others received treatment for some services, but were unable to access care for other conditions or additional episodes of care. In categorizing our findings, VCP care receivers includes Veterans who received any care through $\mathrm{VCP}$ to reflect the reality that successfully receiving care for one issue or service does not ensure receiving care for others. Unsuccessful VCP care seekers include Veterans who were unable to access any care through the VCP.

We identified six themes: general impressions of the VCP (concept and frustration); preferred source of care; facilitators (VA staff facilitation and proactive Veterans); barriers to accessing care through VCP (complexity, lack of responsiveness, lack of local providers, and poor coordination); unintended negative impacts (unexpected responsibility for costs of care, discontinued access to community care); and perceived source of VCP problems (learning curve, leadership, staff, and politics) that impact intention to use the program in the future.

Table 1 Respondents' Age, Gender, and User Status by Site

\begin{tabular}{llll}
\hline \hline & Site 1 & Site 2 & Site 3 \\
\hline Successful VCP users & 6 & 13 & 13 \\
Unsuccessful VCP users & 4 & 4 & 3 \\
Mean age & 67.3 & 68 & 67 \\
Male & 10 & 19 & 16 \\
Female & 0 & 1 & 1 \\
\hline
\end{tabular}




\section{General Impressions}

VCP Concept. The option of receiving care through the VCP when VA care is not available was universally seen as a good idea, with one participant stating, "I'm glad to see they came up with it... it captured my attention right away because I do live 90 miles away from service." However, most Veterans in both groups described challenges using the program and made a clear distinction between the idea of the VCP and its implementation. One participant expressed this common perception, stating "It's a very well-intended, poorlyorchestrated, not well-documented program."

For those who accessed care through the VCP without difficulty, it was, as one Veteran put it, "amazing." These Veterans participation in the VCP reflected a positive change in the VA.

Well I would definitely tell them [other Veterans] that that would be the way to go, you know. Yes, it's most definitely a step up, you know, to be honest with you I can't really say anything bad about the VA or anything like that because I've never really had any issues.Most VCP care receivers, including those who had challenges getting care, felt that the program increased both access to and quality of care:

I think it's great for people who, you know, need to get in and see somebody when they're all booked up. I think it adds to the quality of care, too, because... if the VA is maxed out on appointments I don't think they're going to spend as much time as they would...if they weren't so busy.

Frustration. For some Veterans, there were challenges to getting care through the VCP. For one VCP care receiver, while he successfully received care through the VCP, he felt the challenges were overwhelming enough to leave him "exceptionally scared" of having to go through the process again; "So much of a disaster, I don't want to go back there... I love my doctor, but...."

In contrast to VCP care receivers, unsuccessful VCP care seekers described frustration, disappointment, or anger (often quite intense):

And I was really disappointed! You know, I received excellent care at the VA. They are so efficient and they take such good care of me.... and that holds true for both the [VA] hospital and the VA Clinic.....when they told me it wouldn't be until June...it really burst my bubble, you know? Because I have such faith in the VA, I really do.When describing these negative experiences, Veterans, both VCP care receivers and unsuccessful VCP care seekers, typically were unable to distinguish between VA staff and providers, non-VA providers, and TPA staff. Participants with negative experiences often attributed problems, including those with TPAs and non-VA providers, to VA deficiencies.

\section{Preferred Source of Care}

While a few participants in both groups were unconcerned with where they received care, most presented more nuanced attitudes, expressing an institutional, specialty or individual provider preferences. Additionally, many expressed a desire to choose where they received their care; "I wish we could just go anywhere we wanted to and then the VA picks up the bill."

Institutional Level. At the institutional level, most participants from both groups expressed a clear preference for receiving care through the VA; "I love the VA. I have no problems with the VA whatsoever." However, some participants, especially unsuccessful VCP care seekers, expressed very negative attitudes toward the VA as a source of care; "It's a freakin' mess."

Individual Providers. Despite the frustrations that some Veterans experienced with the VA as an institution, Veterans from both groups described a positive relationship with an individual care provider as the central factor in participants' preferences for care; "I wouldn't give up my primary care provider for the world. She's a VA doc, and she's amazing. So I would go to her before I go to anyone else regardless of where they are."

Some VCP care receivers described how a positive experience with an outside provider, while not diminishing their general affinity for VA care, was the basis for preferences for specific providers and specialties outside of the VA; "I feel confident.... on any other circumstance I'd feel fine going to the VA doctor. I know we have a good ortho department. But this doctor here is familiar with my case."

Specialties. Participants in both groups also distinguished between their general institutional preference and specific specialties and clinics;

I understand I have services available through the VA, and don't get me wrong, I love the VA, and I am so impressed with everything that the Feds do to help me as a Vet....but I have issues with the podiatry clinic at the VA... and I had to go outside of the VA to get services performed. 


\section{Facilitators}

When VCP care receivers described what helped them to get care through the VCP, they focused on the facilitation of individual VA staff and their own initiative.

VA Staff Facilitation. The most common facilitator described by VCP care receivers was proactive VA providers and staff who facilitated the process for the Veteran;

It was a very good man, [Accounts Receivable], he called me and actually got me set up with this thing. Another good person was [RN], and if it wasn't for her, I'd still be bouncing around from phone call to phone call. So those two people did everything they could do, they were super people.However, there is a great deal of inconsistency reported by both groups of Veterans, both within and across sites, regarding VA provider and staff roles in facilitating VCP. While some Veterans reported that their providers, nurses, or other staff initiated their participation in $\mathrm{VCP}$, others were not even sure if their providers were aware of VCP; "I don't know if [my doctor] is aware or not. I did mention it to...the nurse. She didn't know too much about the program itself. It was relatively new."

Proactive Veterans. Several VCP care receivers described themselves as proactive; "I find it very rewarding that I had to be proactive, and make sure the authorizations were done, so you know everything would be paid and covered and everything else." This engagement and tenacity was perceived to be the key factor facilitating the process; "I'm proactive as far as getting the authorization, making sure the authorizations are done, calling into Choice care myself, to make sure if I gotta see a specialist, or whatever, it's covered."

Several Veterans, some VCP care receivers and most unsuccessful VCP care seekers, expressed frustration with the gatekeeping aspects of VCP, and desired a more open system that allowed them to choose their local providers; "If you can't be seen by a VA doctor within 30 days, then you should automatically be able to go and find your own." And; "I think there needs to be something where... if I've done the research I should be able to pick my doctor."

\section{Barriers to Accessing Care Through VCP}

Complexity. Many Veterans in both groups described the VCP process as being quite complex and difficult to use. One Veteran described it as, "a horror story." Frequently in describing their care process, participants were unable to identify who they had talked to and sometimes had difficulty differentiating between VA and TPA staff; "Shouldn't have to jump through hoops to get an appointment, ma'am. Just one person should be able to look at it and say, 'He qualifies, let's go.'"

For some in both groups, tracking the process was an overwhelming task, especially for those with memory issues, or those who lack organizational skills. One Veteran, who reported having a head injury said, "... first time I got prescriptions, it was really odd because I didn't really read the letter.... I had to go dig it up, I had it in a folder somewhere and I couldn't find it."

Lack of Responsiveness. Many Veterans in both groups reported difficulty managing the process was compounded by lack of responsiveness from both VA and TPA; "They told me it would be a week to ten days before they could give me an okay from the program, that I was accepted, but... it was probably a month."

Lack of Local Providers. Many unsuccessful VCP care seekers reported that despite being eligible for care outside of the VA, there were no local participating providers; "[A] lot of the providers in this area don't accept VA payment. ...If I had a clinic in [city] which is like sixteen miles from me, I can't go there because...they won't take it."

Poor TPA-VA Coordination. Some VCP care receivers described a lack of communication and coordination between the VA, TPA, and non-VA providers, including issues with scheduling appointments, care coordination, and billing. The lack of coordination resulted in duplication of services, unnecessary travel, confusion, and anxiety regarding payment for services;

Well, when I got there, it was an ophthalmologic exam. So, I got another eye exam....I filled my prescription there and on my way home I got a call from the [community] eye doctor that they had just got authorization to buy the glasses. I said, no, I got them through the VA already.

\section{Unintended Negative Impacts}

For a few participants, problems with the VCP (complexity, lack of staff responsiveness, and poor coordination of TPA and community providers) resulted in unintended consequences beyond inability to access additional care in the community.

Unexpected Responsibility for Costs of Care. Two participants reported unexpected medical bills for VCP care that had not been resolved at the time of the interviews, and described significant distress resulting from the situation.

If you're living paycheck to paycheck...[and] you get something like this, [that] they're not going to pay a bill that you know is going to be thousands and thousands 
of dollars, that would stress you out. I mean that is a terrible thing to do to a Veteran, to purposely pull the rug out from under them. This participant noted that this problem could lead to community providers being unwilling to participate in the VCP.

And I don't want to stiff my surgeon.... If he gets pushed around on this do you think he's going to take the next Veteran that comes to him? This is a really big deal if you're screwing over...the really good providers that provide care to Veterans.... That's not right.

Discontinued Access to Community Care. Another participant told us that the community-based specialty care he had been receiving was no longer covered after the VCP was implemented.

Well again, with my wound care...initially, I had a doctor that I had outside of the VA who was taking care of everything. And then all of a sudden, midstream, the services were cut. And I think it was due to the change in the program, so that's when I had to go through the VA and get that started again which was an impossibility. I mean even though, he, the specialist at the VA, was trying to get it set up, so I could get the care through the program...we still couldn't get it started.

\section{Perceived Sources of VCP Problems}

Veterans from both groups expressed, unprompted, strong opinions regarding VCP shortcomings.

Learning Curve. Some VCP care receivers attributed problems to reasonable challenges in implementing a new program; "I think there were new people, even in the Choice Program, that may not have been aware of what was going on either. But that's a little human error in there, but you'll have that with a new program, I'm sure."

VA Leadership. Several Veterans, especially unsuccessful VCP care seekers, were frustrated or angry and saw these problems as indicative of poor VA leadership; "Why would you ever send out a letter to all the Veterans when you don't know whether the program works?... Why do you offer something that you don't have the kinks out of?" As another Veteran put it:

It's not being run properly.... The top is responsible for what rolls downhill. It shouldn't be this way, but if you clean the program up and get the right accountability to straighten out where it's needed, I'm sure it will run fine.... with the Veterans Choice Program, one point isn't working properly, so it's affecting the whole machine.

Staff. Some Veterans in both groups described staff (not providers) involved in the VCP to be entitled; "Employees seem to be very entitled, and the only reason they're there is because they need a job." Other Veterans expressed the view that staff were inexperienced and incompetent:

It stinks! Get your act together. If you're gonna put something out there, at least have somebody there to follow up on it. At least have somebody there who knows what the hell they're doing. Stop hiring teenagers or high school graduates, or whatever they are, to answer phones, and giving them a script to follow, and they don't have the common sense or the material or the wherewithal to know what to do.

Politics. Some Veterans, primarily unsuccessful VCP care seekers, attributed problems with the VCP to larger political problems and issues; "This program is a joke. Maybe other people are having no problems with it but as far as I'm concerned, it's a joke. Just another one of those political mushrooms that the Obama administration, Democrats, Republicans, they toss it out just to pacify the Veterans. That's all it is." Another respondent described the VCP as part of a larger history of being let down by the government that transcends the VCP and VA; "[I]t's not just the VA, it's Congress itself. They tell you, 'Oh, yeah. Well, you're heroes,' and all this. Nothing ever gets done."

\section{DISCUSSION}

The VCP's complexity not only poses a barrier to accessing care, but also a challenge to identifying the sources of specific problems. Since most Veterans were unable to distinguish VA staff and providers from non-VA providers and TPA staff, the challenges accessing VCP care were attributed to poor VA leadership and staff, even in cases in which the cause may be beyond the prerogative of VA leadership to solve. These experiences may increase Veterans' negative impression of the VA as an institution, particularly at a time in which the current national discourse regarding the VA focuses predominantly on organizational shortcomings and access problems. ${ }^{21,22}$ Participants' low opinion of the VA and its leadership is in sharp contrast to their reported preference for receiving care at the VA. 
The Veterans we interviewed appear to have negative perceptions of the VA precisely because they value this care when they are able to receive it. ${ }^{23,24}$ This dichotomous experience in which Veterans believe the VA "is a "mess" because they want more VA care potentially has implications for the VA's efforts to improve access. The challenges experienced by these Veterans may impact their willingness to utilize the program in the future, thus undermining the VCP's potential to address the VA's access problem. Actively addressing public perception may be necessary in order to maintain political support to improve access, such as increasing recruitment efforts for providers, nurses and other staff, and increasing VCP reimbursement to attract and retain community-based providers. ${ }^{25}$

These findings are sobering because two of the four identified barriers (complexity and lack of available local providers) are most likely to impact the very Veterans who need access to community care the most: those who have cognitive impairments, more complex health issues, declining self-management capacity, and/or live in small communities.

To address some of these concerns, the House of Representatives and Senate passed legislation (May 16, 2018 and May 24,2018 ) to add $\$ 5$ billion to the VCP to continue operations for the next year, expand private care options available to Veterans and expand private care networks. ${ }^{26-28}$ This legislation allows patients seen within a VA facility in the past 2 years to access private walk-in clinics for minor conditions and creates a commission to evaluate closure of VA facilities. If this legislation is passed, the findings form this evaluation will be useful in informing the implementation of changes to the VCP and ongoing evaluation will be needed to determine if these changes address the problems while retaining the benefits of the VCP.

There are three main limitations in this study: First, potential volunteer bias may result in those who agreed to be interviewed having had experiences that were more remarkable than most, whether positive or negative. Second, complexity of the program made it difficult for participants to provide a high-level of specificity regarding service delivery, care coordination, and problems. Lastly, the convenience sample was not intended to be representative of the general VA population. Although we interviewed Veterans from three VA medical centers, in three of the five geographic regions, their experiences may not reflect the experiences of VA-VCP users nationally. ${ }^{29}$ While the sample size was sufficient to reach thematic saturation, ${ }^{30}$ it was not sufficient to allow for meaningful comparisons across specialties.

Acknowledgements: We thank the following individuals for their contributions to this project: David Aron, $M D$; Sherry Ball, PhD; Lauren Stevenson, PhD; Doreen Di Fiore, PhD; Jeneen Shell-Boyd; Taryn Oestreich, MPH, MCHES; Anne Lambert-Kerzner, PhD, MSPH; Amy Ladebue, BA; Marina McCreight, MPH; Emily Lawrence, MPH; and Kelley Burns, MA.
Corresponding Author: George G. Sayre, PsyD; VA Puget Sound Health Care System, Center of Innovation for Veteran-Centered and Value-Driven Care, Seattle, WA, USA (e-mail: George.Sayre@va.gov).

Funding Information This project was supported by Program Award PEC 15-240 from the United States Department of Veterans Affairs, Quality Enhancement Research Initiative.

\section{Compliance with Ethical Standards:}

Conflict of Interest: The authors declare that they have no conflict of interest.

Disclaimer: The views expressed in this article are those of the authors and do not necessarily reflect the position or policy of the Department of Veterans Affairs or the United States Government.

\section{REFERENCES}

1. Veterans Access, Choice and Accountability Act of 2014, Public Law 113146, 38 USC 101.

2. Department of Veterans Affairs. Summary Veterans Access, Choice and Accountability Act of 2014 (“Choice Act"). Washington, D.C., 2014.

3. Shulkin D. Beyond the VA crisis-becoming a high-performance network. N Engl J Med. 2016; 374(11):1003-5.

4. VHA Office of Inspector General. Interim Report-Review of Patient Wait Times, Scheduling Practices, and Alleged Patient Dealths at the Phoenix Health Care System In: U.S. Department of Veterans Affairs, editor. Washington, DC: 2014.

5. Whitney E. Trump Extends Troubled VA Program that Pays Private Doctors. In: Shots- Health News from NPR. Montana Public Radio, NPR and Kaiser Health News, Montana. 2017. http://www.npr.org/sections/ health-shots/2017/04/19/524738537/trump-extends-troubled-va-program-that-pays-private-doctors. Accessed June 18, 2018.

6. The White House. Remarks by President Trump at Signing of S. 544, The Veterans Choice Program Extension and Improvement Act. Roosevelt Room 2017.

7. Department of Veterans Affairs. Progress Report: Veterans Access, Choice, and Accountability Act 2014. Washington D.C., 2015.

8. West AN, Weeks WB, Charlton ME. Differences among states in rural Veterans' use of VHA and non-VHA hospitals. J Rural Health. 2015; 33(1):32-40.

9. Gellad WF. The Veterans choice act and dual health system use. J Gen Intern Med. 2016; 31(2):153-4.

10. McDonald RA. An Open Letter to America's Veterans. In: U.S. Department of Veterans Affairs, editor. Washington, D.C., 2014

11. TriWest Healthcare Alliance. Frequently Asked Questions About The Veterans Choice Program. TriWest Healthcare Alliance. 2018. Veterans Choice Program Frequently Asked Questions.. Accessed June 18, 2018.

12. Health Net Federal Services. About Veterans Choice Program. Health Net Federal Services. https://www.hnfs.com/content/hnfs/home/va/provider/resources/faqs/vcp.html. Accessed June 18, 2018

13. Mattocks KM, Mengeling M, Sadler A, Baldor R, Bastian L. The Veterans choice act: a qualitative examination of rapid policy implementation in the Department of Veterans Affairs. Med Care. 2017;55:S71-S5.

14. Solberg LI, Brekke ML, Fazio CJ, Fowles J, Jacobsen DN, Kottke TE, et al. Lessons from experienced guideline implementers: attend to many factors and use multiple strategies. Jt Comm J Qual Improv 2000; 26(4): 171-88.

15. Cunningham P, Felland LE, Ginsburg PB, Pham HH. Qualitative methods: a crucial tool for understanding changes in health systems and health care delivery. Med Care Res Rev. 2011:34-40.

16. LaBarge MC, Handelman JM, Mitchell A. Harnessing patient engagement for healthcare system change. Managing a Canadian Healthcare Strategy. 39

17. Mattocks KM, Yehia B. Evaluating the Veterans Choice Program: Lessons for Developing a High-performing Integrated Network. LWW; 2017

18. Damschroder LJ, Aron DC, Keith RE, Kirsh SR, Alexander JA, Lowery JC. Fostering implementation of health services research findings into practice: a consolidated framework for advancing implementation science. Implement Sci. 2009; 4(1):50. 
19. Elo S, Kyngas H. The qualitative content analysis process. J Adv Nurs. 2008; 62(1):107-15. https://doi.org/10.1111/j.1365-2648.2007.04569.x

20. Sandelowski M. Sample size in qualitative research. Res Nurs Health. 1995; 18(2):179-83.

21. Armour S, Kesling B. VA health-system overhaul urged by commission. Wall Street J. 2016.

22. Walsh S, Lawrence Q, Pupovac J. Morning Edition. How congress and the VA left many Veterans without a "Choice": National Public Radio; 2016.

23. Harada ND, Villa VM, Andersen R. Satisfaction with VA and non-VA outpatient care among veterans. Am J Med Qual. 2002; 17(4):155-64.

24. Huang G, Kim S, Gasper J, Xu Y, Bosworth T, May L. 2016 Survey of Veteran Enrollees' Health and Use of Health Care. Rockville, Maryland: Westat 2017.

25. Schlichting NM, Cosgrove DM, Blom DP, Gorman DW, Harvey $T$, Johnson JM, et al. Commission on Care: Final Report. Washington DC, 2016.

26. Yen, Hope. The Associated Press. House OKs Expansion of Private Care at VA, Budget Crisis Fix. New York, New York 2018. https://www.apnews. com/c7b72d6cb07341d88cdalb0dbfa74b5a/House-OKs-expansion-ofprivate-care-at-VA,-budget-crisis-fix. Accessed 5/18/18.

27. Wilkie R. Statement by Acting VA Secretary Robert Wilkie-House Passage of hte Mission Act Washington, D.C.. Department of Veterans Affairs 2018.

28. S. 2372- VA MISSION Act of 2018, 2018.

29. U.S. Department of Veterans Affairs. MyVA Regions-5 Regions Washington, D.C. 2018. https://www.va.gov/opa/pressrel/pressrelease.cfm? id=2672. Accessed May 2, 2018.

30. Guest G, Bunce A, Johnson L. How many interviews are enough? An experiment with data saturation and variability. Field Methods. 2006; 18(1):59-82.

\section{APPENDIX 1: INTERVIEW QUESTIONS}

- Please tell me what you know about the Veterans Choice Program and your eligibility for it?

- Overall, what is your opinion of the Choice Program, and if you could change anything about it what would you change?
- What would you tell other Veterans and/or VHA Leadership about the Veterans Choice Program?

- Has the Choice Program impacted your impression of the VHA, if yes, how?

- Have you ever received care from non-VA providers outside of the Choice Program, and if you wanted to, how would you go about doing that?

- [IF APPLICABLE] Tell me about your experience with the program, including scheduling, getting care, etc.

- [IF APPLICABLE] Please tell me about your experience with the TPA (Health Net or TriWest)?

- [IF APPLICABLE] Please tell me, did you have to pay additional money for the outside care?

- [IF APPLICABLE] Please describe what type of care you received? (e.g., clinic visit, optometry, physical therapy, etc.)

- [IF APPLICABLE] Please describe the experience when you met with the non-VHA clinician/non-VA care provider.

- [IF APPLICABLE] Are your VA doctors aware of your care outside the VA?

- [IF APPLICABLE] Has using the Choice Program improved your health care experience?

- [IF APPLICABLE] Would you prefer to see a VA provider for [type of care] if one was available?

- [IF APPLICABLE] Tell me about any problems or difficulties you have had getting care at a VA facility.

- [IF APPLICABLE] If you were eligible but chose not to participate in the program, please tell us about that. 